\title{
Chronic Periodontitis Does Not Impact Serum Levels of Prostate-specific Antigen
}

\author{
STEPHAN KRUCK ${ }^{1}$, JÖRG HENNENLOTTER ${ }^{1}$, BASTIAN AMEND ${ }^{1}$, MAYA GEIGER ${ }^{1}$, ELITSA FILIPOVA ${ }^{1}$, \\ TIM NEUMANN ${ }^{1}$, VIKTORIA STÜHLER ${ }^{1}$, TINA SCHUBERT $^{1}$, TILMAN TODENHÖFER $^{1}$, \\ STEFFEN RAUSCH ${ }^{1}$, FABIAN HUETTIG ${ }^{1,2}$, ARNULF STENZL $^{1}$ and JENS BEDKE $^{1}$ \\ ${ }^{1}$ Department of Urology, Eberhard-Karls-University, Tuebingen, Germany; \\ ${ }^{2}$ Department of Prosthodontics, Center of Dentistry, Oral Medicine, and Maxillofacial Surgery, \\ Eberhard-Karls-University, Tuebingen, Germany
}

\begin{abstract}
Background/Aim: Chronic periodontitis (CP) has already been associated with altered PSA values in men undergoing biopsy. This study addressed the impact of $C P$ treatment on PSA screening. Patients and Methods: Fifty-two asymptomatic men presenting for $C P$ treatment were prospectively enrolled. Total (t)PSA, free (f)PSA and \%PSA were determined $(n=47)$ before and after therapy. Pre- and post-therapy values were correlated pairwise regarding patients and dental characteristics. Results: Median age was 54 years ( $S D= \pm 7.7$ years) and mean TPSA was $1.3 \mathrm{ng} / \mathrm{ml}$ $( \pm 1.9 \mathrm{ng} / \mathrm{ml})$. $t P S A$ and $\mathrm{fPSA}$ correlated linearly and positively with age $(p<0.002)$. After stratification by age, tPSA/fPSA remained significantly lower in smokers $(p<0.05)$. No other patient or dental factor was associated with tPSA, fPSA, \%PSA. CP therapy had no effect on PSA reduction and did not affect indication for biopsy. Conclusion: The potential influence of CP on PSA testing seems to be excludable in asymptomatic men.
\end{abstract}

Mortality from prostate cancer (PC) has significantly decreased since the introduction of prostate-specific antigen (PSA) testing in 1994 (1). Nevertheless, the use of PSA screening remains controversial reflected by conflicting data from the European Randomized Study of Screening for Prostate Cancer (ERSPC) and the Prostate, Lung, Colorectal and Ovarian Cancer Screening (PLCO) trial $(2,3)$. Recently, Shoag et al. showed that men in the PLCO control group had

Correspondence to: Jens Bedke, Eberhard-Karls-University Tuebingen, Department of Urology, Hoppe-Seyler-Strasse 3, 72076 Tuebingen, Germany. Tel: +49 70712986613, Fax: +49 7071294638, e-mail: jens.bedke@med.uni-tuebingen.de

Key Words: Chronic periodontitis, inflammation, mass screening, prostate cancer, prostate-specific antigen. more cumulative PSA testing than men in the PLCO intervention group (4). Due to this significant limitation, best available evidence can be obtained from ERSPC data. In this context, the ERSPC trial confirmed a $27 \%$ decreased mortality among the screened men (5). Irrespective of current academic debates, PSA screening is still popular in many countries (6-8). Taken together the results of the ERSPC and PLCO trials about 14-16\% of men aged 55-74 years will have elevated PSA levels $\geq 3.0 \mathrm{ng} / \mathrm{mL}$ (9). However, PSA is not cancer-specific and also elevated in non-malignant conditions such as benign prostatic hyperplasia, urinary tract infections, or after prostatic manipulation (10). Beside urologic disorders, additional confounders were recently identified in a large cohort study. Use of aspirin, statins, insulin or metformin were associated with lower PSA levels (11). Elevated PSA entails a high risk of prostate biopsy related complications as well as PC overdiagnosis and -treatment. Recently, Alwithanani et al. reported that periodontal treatment lowered PSA values in men afflicted with chronic inflammation of the periodontal tissue (12). Chronic periodontitis (CP) represents a major health problem in the US, $46 \%$ (representing 64.7 million people) were diagnosed with $\mathrm{CP}$, while moderate $\mathrm{CP}$ was also positively associated with increasing age and male gender (13). Given the presumed high co-incidence of gum disease and elevated PSA levels in men, this prospective trial was designed to clarify the influence of CP on PSA in individuals without urological symptoms.

\section{Patients and Methods}

This study was jointly implemented by the department of Urology and the department of Prosthodontics, Center of Dentistry, Oral Medicine, and Maxillofacial Surgery (University Tübingen, Germany). The protocol was approved by the Institutional Review Board $(657 / 2015 \mathrm{BO} 2)$. Only men $\geq 45$ years with $\mathrm{CP}$ were included in the study. Men with diagnosed malignant or inflammatory 
diseases or any prostate related treatments or symptoms were excluded. After giving written informed consent, full mouth assessments were performed by two dental practitioners, trained in periodontal examination. Probing parameters (CP grade, dental status, bleeding on probing, furcation involvement, vertical bone loss and pocket secretion) were scored prior to the first non-surgical CP therapy and 12 weeks later. CP was defined according to the Centers for disease control and prevention (CDC), in partnership with the American Academy of Periodontology (AAP). Moderate $\mathrm{CP}$ was defined as having $\geq 2$ teeth with interproximal attachment loss of $\geq 4$ millimeters or $\geq 2$ teeth with $\geq 5$ millimeters of pocket depth at interproximal sites. Severe periodontal disease is defined as $\geq 2$ teeth with interproximal attachment loss of $\geq 6$ millimeters and at least one tooth with $\geq 5$ millimeters of pocket depth at interproximal sites (14). PSA testing was only offered to men with moderate/severe periodontitis and a life expectancy $>10$ years according to national guidelines recommendations (15). Nine milliliters of blood were sampled from an arm vein prior to baseline scoring and 12 weeks after therapy. Patients were instructed to avoid vigorous physical, pelvic floor and sexual activity for $48 \mathrm{~h}$ before blood testing. Total (t)PSA, free (f)PSA and PPSA/tPSA ratio (\%PSA) were measured (IMMULITE 2000 PSA assay and analyzer, Siemens Medical Solutions Diagnostics, New York, USA). Conventional non-surgical periodontal therapy consists of mechanical supra- and subgingival tooth debridement (using manual, rotating, and ultrasonic instruments) and instructions in self-administered oral health-care measures. Standard descriptive statistics was used to summarize baseline variables. Baseline and post-treatment values were compared by Wilcoxon signed-rank paired testing, while the Wilcoxon rank-sum test was used to analyze changes in baseline PSA values by individual risk factors. Linear regression analysis was used to determine if serum PSA levels were associated with the patient's age. A $p$-value of $<0.05$ was considered as statistically significant. All data were analyzed using JMP (JMP V. 11.2.0, SAS Institute Inc., Cary, NC, USA).

\section{Results}

A total of 52 men were prospectively enrolled in two dentist centers. Five patients were excluded due to non-compliance. At baseline, all study participants had moderate to severe CP. Baseline characteristics of 47 men are shown in Table I. None of the participants received any prostate diagnostics or treatment during the observation period. The mean tPSA level was $1.3 \mathrm{ng} / \mathrm{ml}( \pm 1.9 \mathrm{ng} / \mathrm{ml})$; only four patients had tPSA levels above the lower ERSPC cut-off ( $\geq 3.0 \mathrm{ng} / \mathrm{ml}$ ). PSA levels correlated linearly and positively with age: $\operatorname{tPSA}\left(\mathrm{R}^{2}=0.19\right.$, $p=0.001)$ and fPSA $\left(\mathrm{R}^{2}=0.18, p=0.002\right)$. At baseline, tPSA levels were only significantly lower in smokers compared to non-smokers $(0.7 \mathrm{ng} / \mathrm{ml} \pm 0.6 v s .1 .9 \mathrm{ng} / \mathrm{ml} \pm 2.4, p=0.001)$. This was also confirmed for fPSA $(0.2 \mathrm{ng} / \mathrm{ml} \pm 0.1 v s$. $0.4 \mathrm{ng} / \mathrm{ml} \pm 0.5, p=0.007$ ), whereas no difference was found for \%PSA. After stratification by age, tPSA and fPSA levels remained significantly lower in smokers $(p<0.05)$. No other patients' related factor, e.g. comorbidities such as diabetes showed impact on PSA levels. In further sub-analysis early onset of $\mathrm{CP}$ disease was more frequently found in smoking
Table I. Patients' characteristics and dental status.

\begin{tabular}{ll}
\hline Patient characteristics & \\
\hline Age, years (SD) & $56( \pm 8)$ \\
Smoking (\%) & \\
$\quad$ Non-Smoker & $25(53)$ \\
$\quad$ Smoker & $22(47)$ \\
Diabetes Mellitus (\%) & $44(94)$ \\
$\quad$ No & $03(6)$ \\
$\quad$ Yes & \\
\hline Dental status & \\
\hline CP Grade (\%) & \\
Moderate & $27(57.5)$ \\
Severe & $20(42.5)$ \\
Dental Status (\%) & $8(17)$ \\
Partial & $38(83)$ \\
Complete & \\
Bleeding on probing $(\%)$ & $17(36)$ \\
Localized & $30(64)$ \\
Generalized & \\
Furcation Involvement (\%) & $26(55)$ \\
No & $21(45)$ \\
Yes & \\
Vertical bone loss (\%) & $22(47)$ \\
No & $25(53)$ \\
Yes & \\
Pocket secretion $(\%)$ & $32(68)$ \\
No & $15(32)$ \\
\hline Yes & \\
\hline
\end{tabular}

SD: Standard deviation; CP: chronic periodontitis.

patients (mean age smoker $v s$. non-smoker: $53.2 \pm 5.8 v s .58 .6$ \pm 8.3 years, $p=0.003$ ). None of the clinical periodontal parameters measured at baseline showed an association with tPSA levels. PSA testing before and after CP treatment revealed no significant differences in tPSA, fPSA or \%PSA (Table II and Figure 1). In overall analyses patients experienced declining tPSA values and PSA doubling time (PSADT: $-0.07 \pm 1.5$ years) with a mean tPSA reduction of $0.06( \pm 0.4) \mathrm{ng} / \mathrm{ml}$. PSADT and absolute tPSA reduction also showed no significant changes in subgroups based on patient or dental parameters. In the four patients (9\%) with biopsy indication (defined by tPSA cut-off $\geq 3.0 \mathrm{ng} / \mathrm{mL}$ ), PSA values and indication for biopsy did not change significantly after $\mathrm{CP}$ therapy (Figure 1).

\section{Discussion}

$\mathrm{PC}$ is the most frequent cancer among males and the strong increase in PC incidence is mainly attributed to PSA screening in asymptomatic men (16). However, elevated PSA levels can result from different prostatic conditions such as benign 
Total PSA ng/ml

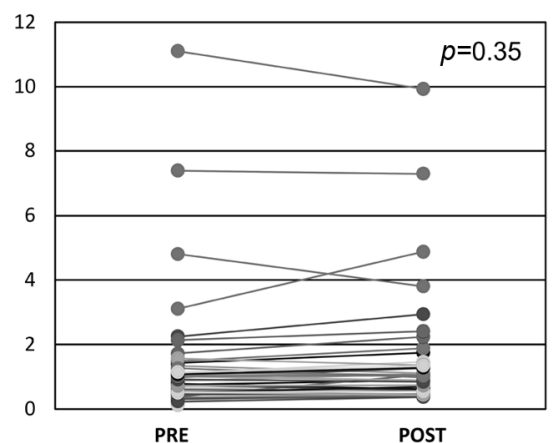

Free PSA (ng/ml)

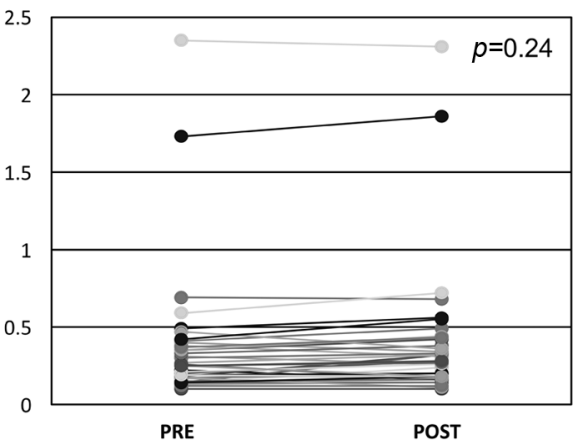

Free / Total PSA Ratio \%

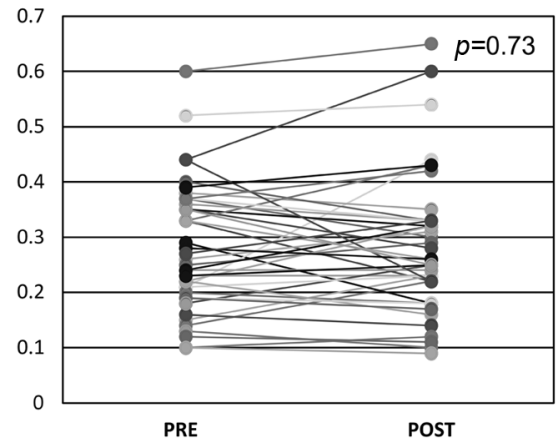

Figure 1. Pairwise analysis of pre- and post-CP treatment PSA (prostate-specific antigen) levels (red: patients with indication for prostate biopsy based on total PSA $\geq 3.0 \mathrm{ng} / \mathrm{ml}$ ).

Table II. PSA Testing before and after CP treatment.

\begin{tabular}{lcccc}
\hline & Pre-therapy & Post-therapy & $p$-Value (Pre- $v s$. Post-therapy) & Change PSA \\
\hline Total PSA ng/ml (SD) & $1.3( \pm 1.9)$ & $1.5( \pm 1.9)$ & 0.35 & $-0.06( \pm 0.4)$ \\
Free PSA ng/ml (SD) & $0.3( \pm 0.4)$ & $0.4( \pm 0.4)$ & 0.24 & $-0.02( \pm 0.1)$ \\
$\%$ PSA (SD) & $0.3( \pm 0.1)$ & $0.3( \pm 0.1)$ & 0.73 & $-0.01( \pm 0.1)$ \\
\hline
\end{tabular}

SD: Standard deviation; PSA: prostate specific antigen; CP: chronic periodontitis.

prostatic hyperplasia, prostate manipulation, or inflammation (10). In 2012, the United States Preventive Services Task Force (USPSTF) assigned a grade of D (recommending against screening) for men of all ages. Since the 2012 recommendation, rates of PSA screening decreased by $3-10 \%$ in all age groups (17). The USPSTF decision against PSA screening for prostate cancer was strongly influenced by the Prostate, Lung, Colorectal, and Ovarian (PLCO) Cancer Screening Trial (3). The PLCO trial showed no PC mortality benefit for men who underwent PSA screening. Recently, Shoag and colleagues reported a higher rate of PSA screening in the control arm compared to the screened arm (4). These results will potentially strengthen the supporters of PSA screening. Meanwhile, a high percentage of men continues to undergo PSA screening in many countries (6-8). Acknowledging the large differences in PSA recommendations, development of personalized screening is inevitable. Previous results suggest a link between inflammation and tPSA elevation among healthy men without urologic disorders (18). While many inflammatory diseases are often well recognized by patients and physicians, CP is often underestimated even in dental examination. It is estimated that approximately half of the US population aged $\geq 30$ years has CP $(19,20)$. Various associations between CP and cardiovascular disease, stroke, pulmonary disease, and diabetes have already been demonstrated (21). Furthermore, periodontal disease was already linked to an increase in male overall cancer risk (22), but turned out not to be relevant for the risk of prostate cancer, at least in non-smokers (23). Interestingly, a recent study confirmed that men having both prostatitis and CP have higher tPSA levels compared to those having either condition alone (24). Based on the similarity in etiopathogenetic factors of prostatitis and periodontitis, a recent report showed an improvement in prostate related symptoms (IPPS) and a decline in PSA levels after periodontal treatment. Although the underlying mechanisms for these phenomena are unknown, authors suggested that CP stimulate prostatic inflammation and prostatic hyperplasia via proinflammatory cytokines. Although, a relation between prostatitis, CP, IPPS and tPSA seemed reasonable, overall decline in TPSA did not reach significance. However, men with a baseline tPSA $>4 \mathrm{ng} / \mathrm{ml}$, showed a reduction in tPSA after treatment (12). Interestingly, this cut-off value ( $>4 \mathrm{ng} / \mathrm{ml})$ was first introduced by Catalona et al. as a threshold to indicate prostate biopsy (25). Today, no clear PSA level exists as an indicator for prostate biopsy. Best evidence can be drawn from the ERSPC and the PLCO trials, which both endorse a lower cut-off $3 \mathrm{ng} / \mathrm{ml}(2,3)$. Beside of optimization of screening 
strategies by redefinition of PSA cut-offs and screening intervals, especially the identification of any factors that can transiently influence PSA levels is urgently need to avoid unnecessary biopsies. Today there are only a few reported confounding variables (i.e., recent ejaculation, manipulations, and urinary tract infections) that can affect PSA levels and indication for biopsy (10). However, due to the high number and prevalence of potential influencing factors in aging males (comorbidities, drugs, etc.), identification of relevant confounders remains challenging. Additionally, further research of interacting parameters is often limited by PSA testing in symptomatic individuals instead of asymptomatic screening candidates (26). To overcome these limitations our prospective trial, included randomly selected men $\geq 45$ years as part of a visit to the dentist. In this scenario, treatment of $\mathrm{CP}$ had no significant influence on tPSA and fPSA levels. PSA levels during $\mathrm{CP}$ therapy were not influenced by patient or dental characteristics. Contrary to the findings in males with symptomatic prostatitis, our results suggest that CP treatment had no beneficial effect on PSA levels in asymptomatic men. However, especially screening participants do not have symptoms and chance of early detection after consultation with the GP or urologist. As far as we are aware, our trial is one of the few studies that prospectively included asymptomatic men to identify epidemiologically-relevant PSA confounders such as CP. Although no significant dental confounders were identified and our study is primarily limited by its small sample size, this trial took a further step towards personalized screening strategies. Interestingly, smoking was associated with lower baseline tPSA and fPSA levels independent of age. Although smoking is considered as a risk factor for PC, the association of smoking and PSA is still controversial $(27,28)$. In conclusion, our data suggest no influence of $\mathrm{CP}$ treatment on tPSA or fPSA levels in asymptomatic men. Smoking was identified as a potential confounding variable in PC screening and therefore introduced as a topic of further investigation.

\section{References}

1 Etzioni R, Gulati R, Cooperberg MR, Penson DM, Weiss NS and Thompson IM: Limitations of basing screening policies on screening trials: The us preventive services task force and prostate cancer screening. Medical care 51(4): 295-300, 2013.

2 Schroder FH, Hugosson J, Roobol MJ, Tammela TL, Ciatto S, Nelen V, Kwiatkowski M, Lujan M, Lilja H, Zappa M, Denis LJ, Recker F, Berenguer A, Maattanen L, Bangma CH, Aus G, Villers A, Rebillard X, van der Kwast T, Blijenberg BG, Moss SM, de Koning HJ and Auvinen A: Screening and prostatecancer mortality in a randomized european study. N Engl J Med 360(13): 1320-1328, 2009.

3 Andriole GL, Crawford ED, Grubb RL, Buys SS, Chia D, Church TR, Fouad MN, Gelmann EP, Kvale PA, Reding DJ, Weissfeld JL, Yokochi LA, O'Brien B, Clapp JD, Rathmell JM,
Riley TL, Hayes RB, Kramer BS, Izmirlian G, Miller AB, Pinsky PF, Prorok PC, Gohagan JK and Berg CD: Mortality results from a randomized prostate-cancer screening trial. $\mathrm{N}$ Engl J Med 360(13): 1310-1319, 2009.

4 Shoag JE, Mittal S and Hu JC: Reevaluating psa testing rates in the plco trial. N Engl J Med 374(18): 1795-1796, 2016.

5 Schroder FH, Hugosson J, Roobol MJ, Tammela TLJ, Zappa M, Nelen V, Kwiatkowski M, Lujan M, Maattanen L, Lilja H, Denis LJ, Recker F, Paez A, Bangma CH, Carlsson S, Puliti D, Villers A, Rebillard X, Hakama M, Stenman U-H, Kujala P, Taari K, Aus G, Huber A, van der Kwast TH, van Schaik RHN, de Koning HJ, Moss SM and Auvinen A: Screening and prostate cancer mortality: Results of the european randomised study of screening for prostate cancer (erspc) at 13 years of follow-up. The Lancet 384(9959): 2027-2035, 2014.

6 D'Ambrosio G, Samani F, Cancian M and De Mola C: Practice of opportunistic prostate-specific antigen screening in italy: Data from the health search database. Eur J Cancer Prev 13(5): 383386, 2004.

7 Tuppin P, Samson S, Perrin P, Ruffion A, Millat B, Weill A, Ricordeau $\mathrm{P}$ and Allemand $\mathrm{H}$ : [prostate-specific antigen use among men without prostate cancer in france (2008-2010)]. Bull Cancer 99(5): 521-527, 2012.

8 van Rij S, Dowell T and Nacey J: Psa screening in new zealand: Total population results and general practitioners' current attitudes and practices. N Z Med J 126(1381): 27-36, 2013.

9 Schröder FH and Roobol MJ: Erspc and plco prostate cancer screening studies: What are the differences? European Urology 58(1): 46-52, 2010.

10 Mottet N, Bellmunt J, Bolla M, Briers E, Cumberbatch MG, De Santis M, Fossati N, Gross T, Henry AM, Joniau S, Lam TB, Mason MD, Matveev VB, Moldovan PC, van den Bergh RC, Van den Broeck T, van der Poel HG, van der Kwast TH, Rouviere O, Schoots IG, Wiegel T and Cornford P: Eau-estro-siog guidelines on prostate cancer. Part 1: Screening, diagnosis, and local treatment with curative intent. Eur Urol 65(1): 124-137, 2016.

11 Nordstrom T, Clements M, Karlsson R, Adolfsson J and Gronberg H: The risk of prostate cancer for men on aspirin, statin or antidiabetic medications. European Journal of Cancer 51(6): 725-733, 2015.

12 Naif Alwithanani; Nabil F. Bissada; Nishant Joshi; Donald Bodner; Catherine Demko; Gregory T. MacLennan; Robert Skillicorn LP and Gupta S: Periodontal treatment improves prostate symptoms and lowers serum psa in men with high psa and chronic periodontitis. Dentistry 5(3): 1, 2015.

13 Eke PI, Dye BA, Wei L, Slade GD, Thornton-Evans GO, Borgnakke WS, Taylor GW, Page RC, Beck JD and Genco RJ: Update on prevalence of periodontitis in adults in the united states: Nhanes 2009 to 2012. J Periodontol 86(5): 611-622, 2015.

14 Page RC and Eke PI: Case definitions for use in populationbased surveillance of periodontitis. J Periodontol 78(7 Suppl): 1387-1399, 2007.

15 Wirth M, Weißbach L, Ackermann R, Alberti W, Albrecht C, Gockel-Beining B, Fröhner M, Hinkelbein W, Miller K and Rubben H: Interdisziplinäre leitlinie der qualität s3 zur fruherkennung, diagnose und therapie der verschiedenen stadien des prostatakarzinoms. AWMF, Düsseldorf, 2011.

16 Arnold M, Karim-Kos HE, Coebergh JW, Byrnes G, Antilla A, Ferlay J, Renehan AG, Forman D and Soerjomataram I: Recent trends in incidence of five common cancers in 26 european 
countries since 1988: Analysis of the european cancer observatory. European Journal of Cancer 51(9): 1164-1187,2015.

17 Fleshner K, Carlsson SV and Roobol MJ: The effect of the uspstf psa screening recommendation on prostate cancer incidence patterns in the USA. Nat Rev Urol 14(1): 26-37, 2017.

18 Elzanaty S, Rezanezhad B and Borgquist R: Association between psa levels and biomarkers of subclinical systemic inflammation in middle-aged healthy men from the general population. Current Urology 9(3): 148-152, 2016.

19 Albandar JM: Underestimation of periodontitis in nhanes surveys. J Periodontol 82(3): 337-341, 2011.

20 Albandar JM, Brunelle JA and Kingman A: Destructive periodontal disease in adults 30 years of age and older in the united states, 1988-1994. J Periodontol 70(1): 13-29, 1999.

21 Pihlstrom BL, Michalowicz BS and Johnson NW: Periodontal diseases. The Lancet 366(9499): 1809-1820, 2005.

22 Michaud DS, Liu Y, Meyer M, Giovannucci E and Joshipura K: Periodontal disease, tooth loss, and cancer risk in male health professionals: A prospective cohort study. Lancet Oncol 9(6): 550-558, 2008.

23 Michaud DS, Kelsey KT, Papathanasiou E, Genco CA and Giovannucci E: Periodontal disease and risk of all cancers among male never smokers: An updated analysis of the health professionals follow-up study. Ann Oncol 27(5): 941-947, 2016.

24 Joshi N, Bissada NF, Bodner D, Maclennan GT, Narendran S, Jurevic R and Skillicorn R: Association between periodontal disease and prostate-specific antigen levels in chronic prostatitis patients. J Periodontol 81(6): 864-869, 2010.
25 Catalona WJ, Smith DS and Ornstein DK: Prostate cancer detection in men with serum psa concentrations of 2.6 to 4.0 $\mathrm{ng} / \mathrm{ml}$ and benign prostate examination: Enhancement of specificity with free psa measurements. JAMA 277(18): 14521455, 1997.

26 Meigs JB, Barry MJ, Oesterling JE and Jacobsen SJ: Interpreting results of prostate-specific antigen testing for early detection of prostate cancer. J Gen Intern Med 11(9): 505-512, 1996.

27 Algotar AM, Stratton SP, Ranger-Moore J, Stratton MS, Hsu $\mathrm{CH}$, Ahmann FR, Nagle RB and Thompson PA: Association of obesity and smoking with psa and psa velocity in men with prostate cancer. Am J Mens Health 5(3): 272-278, 2011.

28 Kristal AR, Chi C, Tangen CM, Goodman PJ, Etzioni R and Thompson IM: Associations of demographic and lifestyle characteristics with prostate-specific antigen (psa) concentration and rate of psa increase. Cancer 106(2): 320-328, 2006.

Received April 30, 2017

Revised May 11, 2017

Accepted May 15, 2017 